\title{
Understanding the Molecular Mechanism of Phytoconstituents as Tyrosinase Inhibitors for Treatment of Hyperpigmentation
}

\author{
Lata Kothapalli $^{1 *}$, Pooja Sawant ${ }^{2}$, AshaThomas ${ }^{1}$, Ravindra Wavhale ${ }^{1}$, Komal Bhosale ${ }^{2}$
}

${ }^{1}$ Faculty, Department of Pharmaceutical Chemistry, Dr. D. Y. Patil Institute of Pharmaceutical Sciences and Research, Gaikwad Haraibhau Vinayan Rd, Sant Tukaram Nagar, Pimpri Colony, Pimpri-Chinchwad, Maharashtra 411018, India

${ }^{2}$ Research Scholar, Department of Pharmaceutical Quality Assurance, Dr. D. Y. Patil Institute of Pharmaceutical Sciences and Research, Gaikwad Haraibhau Vinayan Rd, Sant Tukaram Nagar, Pimpri Colony, Pimpri-Chinchwad, Maharashtra 411018, India

\begin{abstract}
DOI: $\underline{10.36348 / \text { sjmps.2021.v07i02.010 }}$
| Received: 08.01.2021 | Accepted: 20.01.2021 | Published: 27.02.2021

*Corresponding author: Lata Kothapalli
\end{abstract}

\section{Abstract}

Skin Pigmentation is a phenomenon in which the accumulation of melanin occurs due to various factors and leads to skin tanning and other skin disorders. Now a day's human beings are more conscious about quality of life and appearance. With this fascination towards various skin whitening or glowing agents is gaining more adherences. While synthetic chemicals approved as skin whitening agents have got the due recognition in market, the possible adverse effects on sensitive skin creates a question regarding their use. The natural plant extracts available as tyrosinase inhibitors are mostly phenolic entities. In this review the inhibitory effect of phenolic compound and flavonoids on tyrosinase enzyme using molecular simulations is studied. The insilico study of flavonoids helps to predict the mechanism of inhibition as well as identification of potential natural tyrosinase inhibitors. This review is oriented to understand the tyrosinase inhibitory activity of an array of phenolic compounds with emphasis on flavonoids to explain how position of the substituents and their interaction with the enzyme can be correlated for the efficacy against the tyrosinase activity.

Keywords: Flavanoids, Tyrosinase inhibitor, Hyperpigmentation, Molecular docking.

Copyright (C) 2021 The Author(s): This is an open-access article distributed under the terms of the Creative Commons Attribution 4.0 International License (CC BY-NC 4.0) which permits unrestricted use, distribution, and reproduction in any medium for non-commercial use provided the original author and source are credited.

\section{INTRODUCTION}

Skin hyperpigmentation is a major cause of concern and is caused by sun exposure, pregnancy, hormonal contraception, family history [1]. With a high prevalence in the Indian population. Melanin level are twice the concentration of normal skin and contributes to darker skin phenotypes, where the pigment is expressed in melanocytes present in the basal layer of the epidermal layer [2,3]. Melanosome degradation rates vary in darker skin when compared with lighter skin types as studied by Vashi and Kundu, 2013 [4]. Also the melanin content and dispersion pattern of melanosomegives the required protection against UV radiation[5]. The hyper pigmentation is phenomenon in which the accumulation of melanin will leads to several skin disorders. Among the pigmentary disorders lentigines and melasma, postinflammatory hyperpigmentation, and dark eye circles are most common [6]. Liver spot (senile lentigo) is skin disorder in which small pigmented spot on skin having diameter of $1 \mathrm{~mm}$ which is mainly observed in people above the age of 40years. Excessive exposure to ultraviolet radiation expresses the melanocytes and formation of melanin pigment in keratinocytes [7,8]. Vitiligo is a condition which affects any part of skin where pigment cells stop functioning and lead to progressive appearance of patches or discolouration of skin colour $[9,10]$. Ephelides (freckles) are dark brown spot on skin, caused due to exposure to sun rays or also as genetic makeup, over production of melanin and irregular distribution of melanin lead to irregular patches on skin. Melasma (chloasma or mask of pregnancy) is predominant in women because of hormonal changes during pregnancy [11].

In the melanogenesis process, Tyrosinase enzyme presents a potential target for inhibition as it is a rate limiting enzyme [12]. The enzyme also is expressed in fruits and vegetables besides the fungi due to which the browning is seen [13].

For the same, huge demand for novel, safe andpotent tyrosinase inhibitors is increasing and has application in food and cosmetic industry [14]. The skin whitening agents are also used in scars, acne to make the skin uniform in colour. As there is increase in demand for tyrosinase inhibitors, various tools for screening of compounds, invitro and invivo assay and 
design of synthetic inhibitors are undergoing rapid development. Various microbial species express tyrosinase enzyme like Streptomyces glaucescens, Agaricus bisporus and Neurospora crassa. Mushroomtyrosinase enzyme obtained from Agaricus bisporusiswidely used for screeningtyrosinaseinhibitory activity by various small molecules and can be proven viainsilico study. The structural features of Mushroom tyrosinase have highest similarity with human tyrosinase compared to other tyrosinase enzyme sources [15] and the one studied by Ismaya et al., 2011 as crystal structure composed of tetramer with the co crystallised ligand tropolone as inhibitor has been widely used for understanding the binding interaction with various inhibitors (PDB code 2Y9X) [16]. Another crystal structures of tyrosinase used for the study of inhibitors is a well resolved dimer from Bacillus megaterium [17]. The computational drug design tools for molecular modelling can be an important tool for understanding the anti tyrosinase activity of compounds using the lead from natural resources [18].

This review is oriented to understand the tyrosinase inhibitory activity of an array of phenolic compounds with emphasis on flavonoids to explain how position of the substituents and their interaction with the enzyme can be correlated for the efficacy against the tyrosinase activity.
The importance of structural features of polyphenols in treating hyperpigmentation using molecular modelling supported by enzyme inhibition assay can help in development of analogs using the phenolics as lead. A systematic search was performed on PubMed, Scopus, Embase, Medline, databases using the words "tyrosinase inhibitor, phytoconstituents docking, skin lightening agents, hyperpigmentation and data was collected over the last 20 years.

\section{Melanin Biosynthesis}

Melanin is a Greek word i.e. melanos means dark. Chemically melanin is a blend of various biopolymersobtained from serially oxidised derivatives of tyrosine [19]. Skin, hairs, and eye (ciliary body and choroid) with parts of the mammalian cerebrum contain melanin, which additionally spread in theliver, the gaps in layer of serous membrane and amphibian organs [20]. Tyrosinase present in melanocytes helps in synthesis of pigment melanin and stored in melanosomes. Melanocyte produces two kinds of pigment that is eumelanin and pheomelanin by RaporMason Pathway [21].

Biosynthesis of melanin begins with Ltyrosine which is oxidised to L-3, 4dihydroxyphenylalanine and later to dopaquinone with the assistance of enzyme tyrosinase [22].

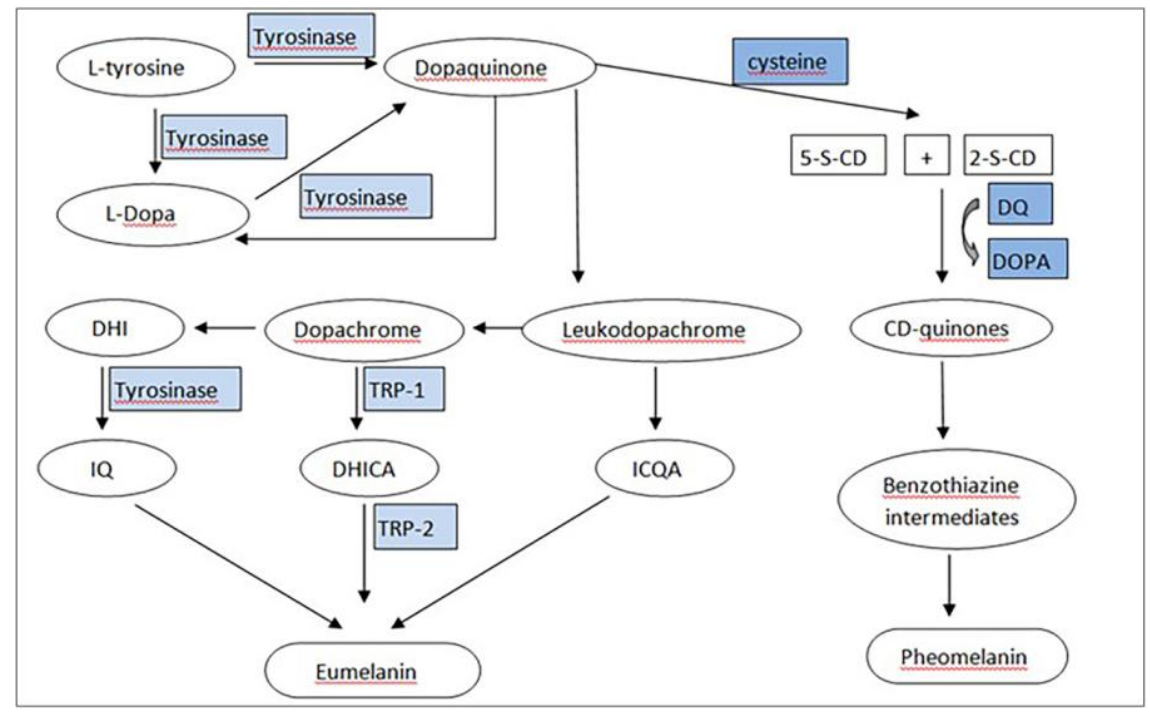

Fig-1: Melanin biosynthesis

As seen in Fig-1, Dopaquinone by cyclization form leukodopachrome and further by oxidation to dopachrome and Indole-2 carboxylic acid - 5, 6quinone(DHI). In presence of enzyme Tyrosine Related Protein-1 (TRP-1) dopaquinone is converted into dihydroxyindole-2-carboxylic acid (DHICA) and oxidized into dihydroxyindole (DHI) [23]. Further DHI by oxidation with tyrosinase enzyme converts into indolequinone(IQ). By polymerization of DHICA, IQ and ICAQ result in the formation of eumelanin (blackbrown). On the opposite side, dopaquinone modifies to glutathionyldopa or cysteinyl dopa with the help of glutathione or cysteine and these are further converted to pheomelanin (red-yellow) by forming benzothiazine as intermediate [24].

Microphthalmia associated transcription factor (MITF) controls the melanin biosynthesis and control the gene expressions of TRP-1, TRP-2, and tyrosinase. 
The upregulation of MITF activity leads to an increase in the synthesis of melanin and downregulation of MITF activity leads to a decrease in the synthesis of melanin [25].

\section{Role of tyrosinase enzyme}

Enzymes are activated by metal ions as cofactors. Enzyme Tyrosinase is also a metalloenzyme with two copper ions and ismembrane-bound type3glycoprotein. X-Ray Crystallographic structure of tyrosinase obtained from PDB databaseshows active site with a huge vacant space surrounded with six histidine residues attached with copper ion which makes the structure of enzyme highly flexible. Active site of enzyme has a substrate binding pocket which can orient based on theflexibility and position to fit the substrate [26, 27]. The measurement of cell size and count of melanosomes helps in understanding the regulation of melanin formationat the cellular level while expression of enzymes involved in melanin synthesis is driven by signaling pathways [28].

\section{Tyrosinase inhibition mechanism:}

Tyrosinase enzyme inhibition occurs in the same way as all enzymes react with inhibitors based on two different mechanism namely suicide inactivators and true inhibitors.Suicide inactivators are specific tyrosinaseinactivators where in the substrate brings about conformational changes with the help of solvent molecule and alters the tertiary and quaternary structures of tyrosinase in presence of inhibitor leading to suicide inactivation [29]. Land et al., D-tyrosinase is an example of irreversible inhibitor of the enzyme and stop the melanin formation provoked by UV irradiation or $\alpha$-MSH [30]. True Inhibitors compete with the substrate for binding in active site of the enzyme and are the competitive inhibitors E.g. Morin, Hesperitin [31]. Noncompetitive inhibitors like 7,8,4trihydroxyflavoneand Mixed (competitive and uncompetitive) Inhibitor such ascinnamic acid, thymol analogues [32] have multiple binding in active pocket of enzyme or in allosteric site of the enzyme-substrate complex while derivatives like Barbarin are Uncompetitive Inhibitor. Some examples of flavonoids are as mentioned in Table-1.

Table-1: Different Flavanoids with the type of inhibition

\begin{tabular}{|c|c|c|c|c|}
\hline $\begin{array}{l}\text { Classes of } \\
\text { flavonoids }\end{array}$ & Biological source & Chemical constituent & $\begin{array}{l}\text { Mechanism of } \\
\text { tyrosinase inhibition }\end{array}$ & IC $_{50}$ value \\
\hline $\begin{array}{l}\text { Flavones and } \\
\text { dihydroflavone }\end{array}$ & $\begin{array}{l}\text { Heart wood of } \\
\text { Artocapusaltilis }\end{array}$ & 7,8,4trihydroxyflavone & Noncompetitive & $10.31 \pm 0.41 \mu \mathrm{M}$ \\
\hline Hydroxyflavone & $\begin{array}{l}\text { Heart wood of } \\
\text { Artocapusaltilis }\end{array}$ & Baicalein & Mixed & $0.11 \mu \mathrm{M}$ \\
\hline Flavanoles & Cudraniacolchinchinens & Morin & $\begin{array}{l}\text { Competitive \& } \\
\text { reversible }\end{array}$ & $8.13 \mu \mathrm{M}$ \\
\hline Flavanones & Citrus fruit & Hesperetin & $\begin{array}{l}\text { Competitive \& } \\
\text { reversible }\end{array}$ & $11.25 \mu \mathrm{M}$ \\
\hline $\begin{array}{l}\text { Flavanolsand } \\
\text { flavan-3,4-diols }\end{array}$ & $\begin{array}{l}\text { Extract of stem and fruit } \\
\text { of Clausenalansium }\end{array}$ & $\begin{array}{l}\text { Epicatechin, } \\
\text { Gallocatechin, } \\
\text { Epigallocatechin }\end{array}$ & $\begin{array}{l}\text { Mixed and } \\
\text { competitive inhibition }\end{array}$ & $\begin{array}{l}23.6 \mu \mathrm{M} \\
7.0 \mu \mathrm{M}\end{array}$ \\
\hline Curcuminoids & $\begin{array}{l}\text { extract of Curcuma } \\
\text { xanthorrhiza }\end{array}$ & $\begin{array}{l}\text { Curcumin, } \\
\text { demethoxycurcumin and } \\
\text { xanthorrizol }\end{array}$ & Competitive & $267.3 \pm 6.1 \mu \mathrm{M}$ \\
\hline
\end{tabular}

\section{Polyphenols as Tyrosinaseinhibitors for treatment of hyperpigmentation}

Living organisms develop their own protective pathways to fight against the adverse surroundings. One such pathway beneficial against excessive exposure to harmful ultraviolet radiation is the Melanin pathway (Skin tanning) and the control on the melanin pathway is done by the innumerable sources of tyrosinase inhibitors [33]. Various scientists have studied tyrosinase inhibitors from natural sources like plant, fungi and marine life to understand their structural features to understand the structure-activity relationship (SAR) and further modify the existing compounds to overcome issues related to stability and efficacy [34]. Natural products have gained more attention in cosmetics as compared to synthesized compound specially the plant concentrates being studied to discover new lead compounds. A number of researchers also studied the inhibitors for overcoming the adverse and toxic effects especially when used for food storage and medicinal applications. Besides this an ever increasing demand around the globe is towards skin glowing and skin whitening products [35]. The understanding of the structural features of the phytoconstituents will help in developing more stable and efficient derivatives for the treatment. The computational drug design tools like structure based drug design where in molecularmodelling can be an important tool for understanding the antityrosinase activity of compounds using the lead from natural resources.

\section{Polyphenols}

Plant polyphenols make an amalgam of compounds with multiple phenolic functionalities. These compounds are secondary metabolites formedby 
Lata Kothapalli et al., Saudi J Med Pharm Sci, Feb, 2021; 7(2): 135-144

most higher plants and contribute for severalbiologicalactivities. Nguyen et al., studied the methanolic extract of heartwood of Artocapusalti. liscontaining about 13 phenolic compounds against the tyrosinase inhibitory activity wherein it was seen that curcumin, desmethoxycurcumin and p-coumaric acid were more potent than kojic acid [36]. Kim D et al., 2006 further carried out molecular modeling of the pcoumaric acid and phenyl thiourea(PTU) as standard depigmenting agent used in understanding the blocking of pigmentation process in zebrafish embryo.Thebinding interaction of Chain A tyrosinase enzyme (PDB ID = 3NQ1). with standard PTU and pcoumaric acid was analysed and compared with the kojic acid using the PyRx,a software of Autodock 4. The binding interaction of p-coumaric acid was different from those seen with the standard. Kojic acid interacted with Pro201, Arg209 via Pi-Alkyl interactions while Gly200 showed Carbon-Hydrogen bond. Interaction with p-coumaric acid with dock score of $-6.00 \mathrm{kcal} / \mathrm{mol}$ involved five amino acid residues namely H-bonding with Gln242, His245, His279 and Pi-sigma interaction with Ile243. It was seen that PTU binding pattern did not overlap with kojic acid site. For PTU, $\pi-\sigma$ interaction were seen with Val218 and while Gly216with H-bonding, Ala221showed $\pi$-Alkyl interaction, HIS208 showed Pi-Pi stacked interaction with binding score of $-5.53 \mathrm{kcal} / \mathrm{mol}$. With this modeling study it was concluded that $\mathrm{p}$-coumaric acid and PTU show different binding pattern within the active site of the enzyme. The experimental study with zebrafish model and molecular docking correlated that p-coumaric acid can be an important lead molecule to inhibit dermal pigmentation [37].

\section{Flavonoids}

Flavonoids are a huge class of compound among natural products and are utilized broadly as lead compounds or drugs. Looking into the biosynthetic pathway for the flavonoids, it is seen that chalcone initiates the synthesis of flavonoids as reviewed by Falcone et al., 2012 [38]. Polysubstituted derivatives such as 2,4,3' , 4'-hydroxychalcone and 2,4,2',4'hydroxychalcone present $\mathrm{IC}_{50}$ of 0.2 and $0.02 \mathrm{M}$, respectively against the monophenolase enzyme as demonstrated by Khatib et al., 2005 [39]. Further few more studies on the hydroxyl substituted derivatives were done by Shimizu et al., 2000 [40] using phytoconstituents and synthetic analogs and Ohguchi et al., 2003 [41] explained importance of number and place of phenolic hydroxyl group on the flavonoids impact the inhibition of tyrosinaseenzyme. Kim D et al., 2006 correlated the Stern-Volmer quenching constants values with the IC 50 values of about 25 flavonoids when tested against the Tyrosinaseenzyme [42]. The number of phenolic hydroxyl on the two aromatic rings (Fig-2) of flavonoid structure, can significantly impact inhibition of tyrosinase enzyme. The hydroxyl groups of $\mathrm{A}$ and $\mathrm{B}$ rings separated by the etherical bond of the C (pyran) ring mainlycontributein the tyrosinase inhibitory activity. The experimental finding were confirmed with molecular docking studies. For the same,homology modeling was used to prepare mushroom tyrosinasewith crystal structure (PDB code, 1BT3) of Catechol oxidase using the template Octopus hemocyanin (PDB code, 1JS8). The docking result on prepared tyrosinase enzyme showed that the catechol group and copper ions complex well thereby inhibiting enzyme activity. Further activity is lost or decreases with additional hydroxyl groups which add to steric hindrance.

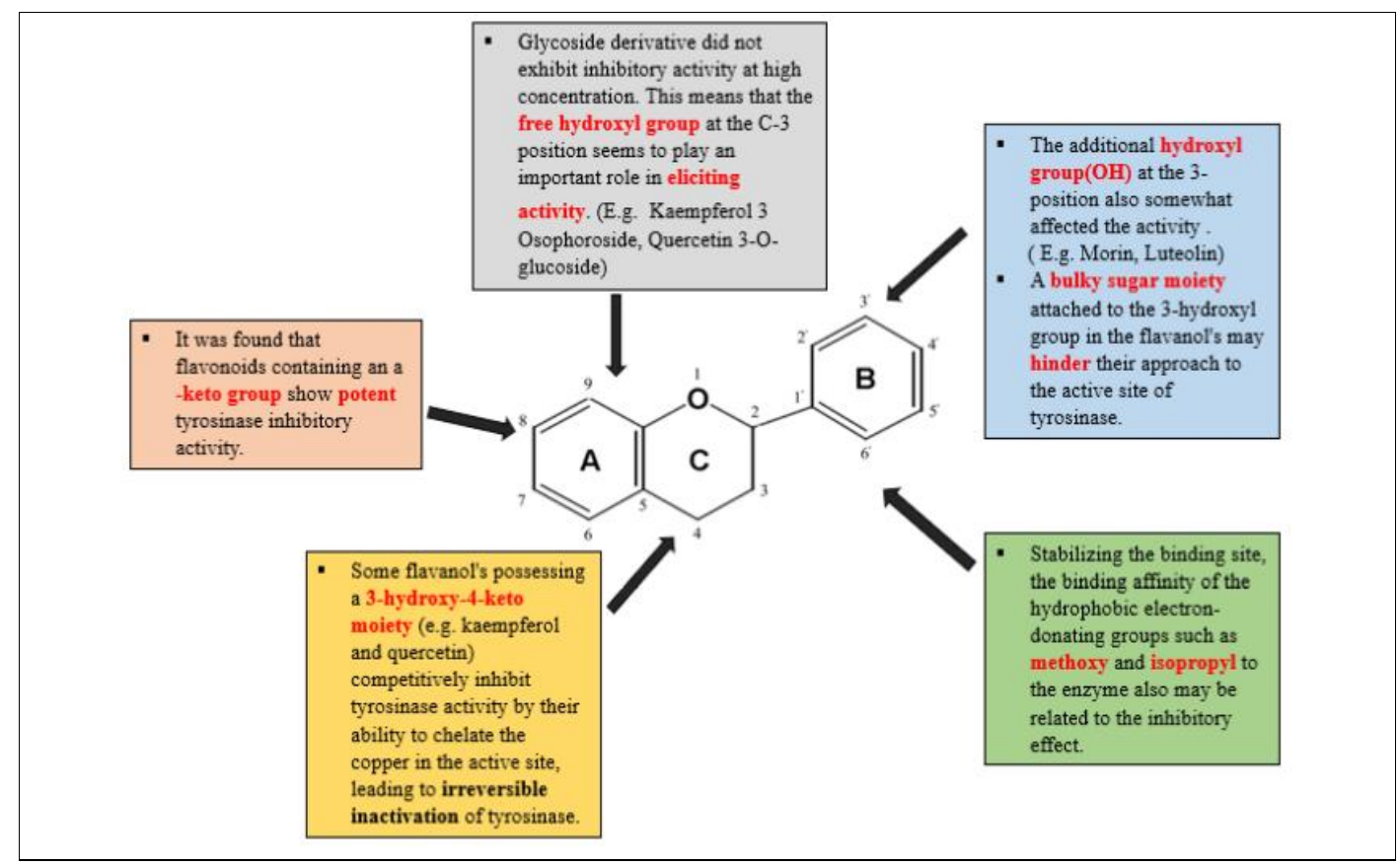

Fig-2: General structure of flavonoids 


\section{Flavones and Dihydroflavone}

The derivative of flavones, that is $7,8,4$ ' trihydroxyflavone which occur extensively in petals and foliage of the plant and having widespread pharmacological activity. Shang et al., 2018 carried out experiments to correlate the mechanism for tyrosinase inhibition with the molecular docking simulation for
7,8,4'- trihydroxyflavone. When taking varied concentration of substrate and inhibitor, it was observed that the enzyme inhibition with $\mathrm{Ki} 9.50 \pm 0.40 \mu \mathrm{M}$ is reversible and non- competitive. It inhibits both diphenolase and monophenolase activity in a reversible and non-competitive manner with IC50 value of $10.31 \pm 0.41 \mu \mathrm{M}$ and $12.95 \mu \mathrm{M}$ respectively [43]

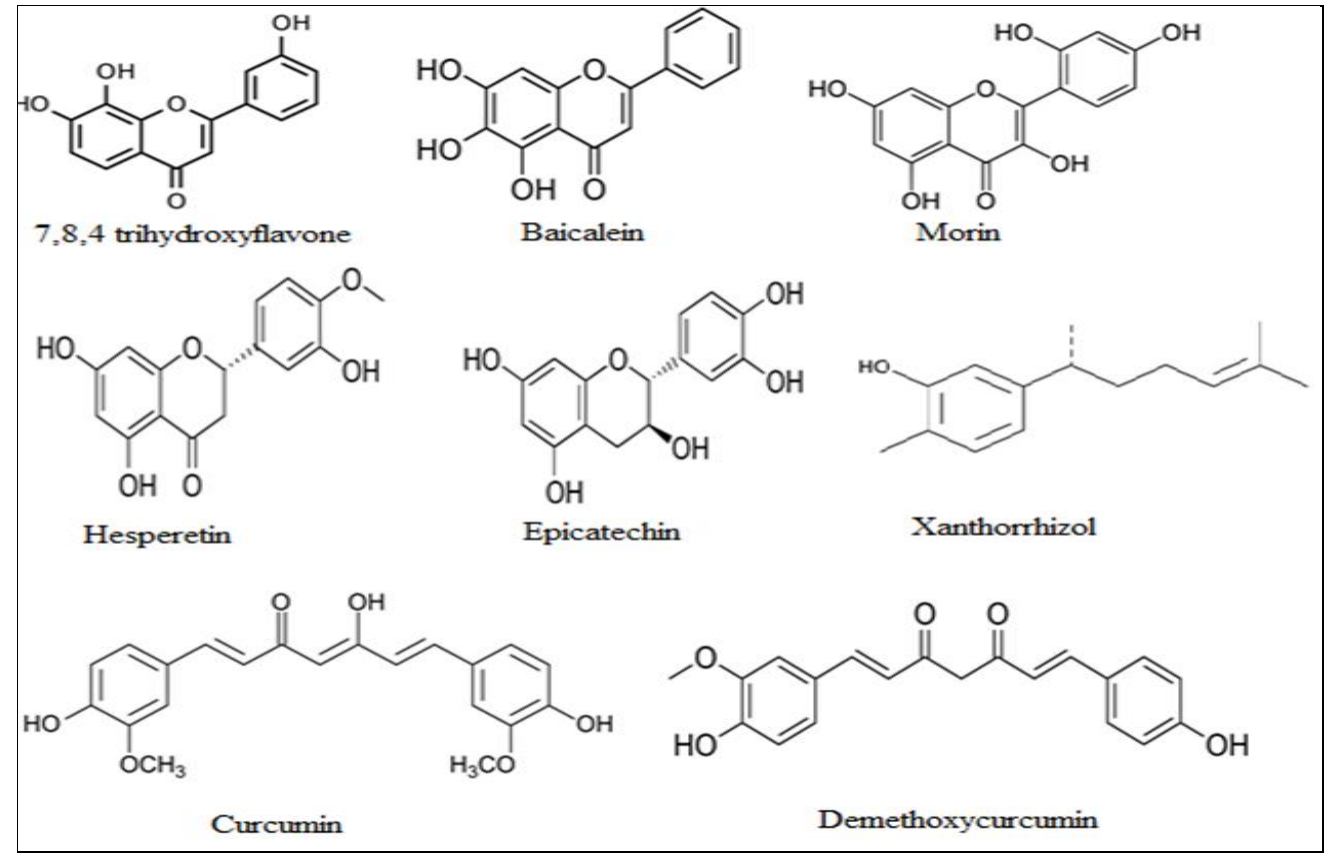

Fig-3

For 7,8,4-trihydroxyflavone (Fig-3) binding to tyrosinase enzyme is through conformational changes. The mushroom tyrosinase ( PDB 2Y9X) active site has twosets of three histidineresidues namely Set A (His61, His85 and His94) and Set B with His259, His263 and His294 that couple with copper ions. 7,8,4 Trihydroxy flavone stations itself in the active site of catalytic domain surrounded by Tryptophan amino acid and is explained by the binding affinity between protein and ligand. Lowest binding free energy is ranked as best confirmation, 7,8,4trihydroxy flavone showed the binding score $-7.4 \mathrm{kcal} / \mathrm{mol}$ which represents binding interactions. The oxygen of carbonyl group of Ring $\mathrm{C}$ acts as HBA for Hydrogen bond interactionwhile 7-OH group is $\mathrm{HBD}$ in ring $\mathrm{A}$ with His 244 and Met280 residues with a bond length of $3.34 \mathrm{~A}^{0}$ and $3.07 \mathrm{~A}^{0}$ respectively. The van der Waal force and hydrophobic interaction were seen between carbamoyl group of Asn260 and phenyl ring of 7,8,4 trihydroxyflavone respectively, which is seen to help in improving stability of binding interaction.

Another flavone Baicalein is chemically 5,6,7trihydroxyflavone which is obtained from roots and aerial parts of Chrysanthemum morifolium, Artemisiaannua and Oroxylumindicum (Indian trumpet flower) [44]. Baicalein exhibit inhibition at a later stage of oxidation diphenolase enzymewith mixed type of inhibition [45]. Baicalein Fig-3 shows inhibition of tyrosinase with the conformational changes in the structure of enzyme. Along with tyrosinase inhibition baicalein shows multiple activities such as antioxidant properties and is safe molecule [46]. Nihong Guo et al., estimated the active site for binding interaction is present at the bottom of the cavity of tyrosinase. From docking studies carried out using the same tyrosinase enzyme (PDB: 2Y9X), intermolecular interaction confirmed the binding between baicalein and tyrosinase which effectively produced docking score $6.20 \mathrm{kcal} / \mathrm{mol}$ for binding conformation. Several adjacent residues are His85, Val 248, Phe264, Met280, Ser282, Val283; Ala286 helps to form hydrophobic interaction with benzene ring and increases stability of binding interaction. Phenolic hydroxyl group(C-7) of baicalein and carbamoyl oxygen atom of Met 280 residue form hydrogen bonding which stabilizes the complex. C-7 hydroxy group was considered very essential for enhancing its inhibitory activity against tyrosinase.

Vander waals interaction are seen between the carbamoyl group of Asn260 and baicalein. It also involves pi -pi interaction with His85 and Phe264 and pi- $\sigma$ interaction with residues Val283 [47, 48]. 
Lata Kothapalli et al., Saudi J Med Pharm Sci, Feb, 2021; 7(2): 135-144

\section{Flavanols}

Morin is a flavones analog (3,5,7,2,4pentahydroxyflavone) (Fig-3) isolated from Cudrania colchinchinensis and Cudrania

tricuspidata (family:Moraceae) is tyrosinase inhibitor an essential bioactive flavonoid compound studied by Zheng et al., 2011 [49]. It is widely present in onion, guava leaves and seaweeds and displaywide spectrum of activities against inflammatory mediators and antioxidant activities [50,51]. Morin is a reversible and competitive inhibitor and shows conformational changes in the enzyme (IC50 value $8.13 \mu \mathrm{M}$ ) [52].

Another study done by Wang, Y et al., explained the inhibitory action of Morin using the circular dichroism spectral study along with docking carried out using PDB code 2 Y9X. The study explained that morin when interact with tyrosinase induces a rearrangement followed by some conformational changes in the enzyme. Morin binds in hydrophobic cavity surrounded by amino acid residues His85, His94, His244, His259, Asn260, His263, Phe264, Met280, Gly281, Val283 and His296. Hydrogen bonding is mainly between His85 and His 244 and C-3 and C-5 hydroxyl group of morin respectively. Thetyrosinase inhibition displayed by morin is due to the fitting of morin into the active site of catalyticdomain which does not interfere with L-DOPA, however Morin shows conformational changes in tyrosinase [53].

\section{Flavanones}

Hesperetin is chemically (3,5,7-trihydroxy-4methoxyflavanone) Fig-3) is abundantly present in citrus fruits and the medicinal herbs of family Rutaceae, Rosaceae, Leguminosae [54, 55]. Hesperidin is theglycoside of hesperitinand has been reported to show anti-inflammatory, anti-carcinogenic, anti-hypertensive, anti-atherogenic, antiviral and antioxidant activity [56].

Yue-Xiu Si et al., 2012 evaluated the tyrosinase inhibitory mechanism with the help of kinetic analysis and computational simulation with hesperitin as the inhibitor and kojic acid as standard. It was shown that hesperitin showed a competitive inhibition with $\mathrm{IC}_{50}$ value $11.25 \pm 1.73 \mathrm{mM}(\mathrm{n}=3)$. Hesperetin enter the active site of the enzyme by competing with L-dopa. Docking was carried out using AutoDock4.2, where the binding score for hesperiin was $-5.67 \mathrm{kcal} / \mathrm{mol}$ while kojic acid had binding energy $-3.91 \mathrm{kcal} / \mathrm{mol}$. Hesperetin binds into the active site of enzyme and reversibly chelate with copper bound to the three Histidine residues (His61, His85, and His259)and modify the hydrophobic surfaces. Hydrogen bonding interactions are also seen between 5-OH and 7-OH of substrate with Met280, His61, His85, His259 residues. Computational simulations carried out by $\mathrm{Si} \mathrm{YX}$ et al., 2012 also confirmed similar binding pattern [57].

\section{Flavanols and flavan-3,4-diols}

Wei-Ming Chai et al., 2014 studied proanthocyanidins (flavan-3-ol) (Fig-3) present in various fruits and its different parts namely pericarp of Kiwi fruit (Actinidiasinensis),.Avocado fruit (Perseaamericana) [58] and fruit seed of Chinese hawthorn (Crataeguspinnatifida B) [59]. Proanthocyanidins extracted from fruit pericarp of Clausenalansium (Lour.) Skeels showed inhibitory activity in concentration dependent manner withIC $\mathrm{C}_{50}$ values calculated to be $23.6 \pm 1.2$ for monophenolase a nd $7.0 \pm 0.2 \mu \mathrm{gmL}^{-1}$ against diphenolase. In addition, the proanthocyanidins also exhibited cell proliferation inhibition with suppression of melanin production evaluated on B16 mouse melanoma cells. RP HPLCESI-MS chromatographic analysis of the treated proanthocyanidins thiolytic products, prodelphinidins (PD) were in greater proportion to procyanidins (PC) and accounts for the enhanced activity against tyrosinase at every step of melanogenesis.

\begin{tabular}{|l|l|l|}
\hline $\mathrm{R}$ & Flavan-3-ol & Proanthocyanidines \\
\hline $\mathrm{H}$ & Epicatechin & Procyanidin \\
\hline $\mathrm{OH}$ & Epigallocatechin & Prodelphindin \\
\hline
\end{tabular}

On taking up the molecular docking studies using the MOE (molecular operation environment, 2010) study, Tyrosinase enzyme obtained from Streptomyces castaneo globisporus (oxy-form) bound with copper and stabilized with a caddie protein (PDB code $1 \mathrm{WX} 2$ )was selected as the protein model and was refined to remove the caddie protein. The hydroxyl groupspresent in B ring of the proanthocyanidins interact withthe two copper ions, and was further correlated by fluorescence quenching. Epicatechin shows binding interaction of copper with His85, His61 and Phe264 residues, and other interaction with His263, Met280, Val248. Epigallocatechin shows interaction of copper ion with Asn260 and Phe264 and shows hydrogen binding interaction with His244 residue. Gallocatechin shows interaction with Phe264, His85, Val283, His263 residues [60].

\section{Curcuminoids}

$\begin{array}{ccr}\text { Curcumin, } & \text { demethoxycurcumin } & \text { and } \\ \text { xanthorrizol (Fig-3) } & \text { obtained } & \text { from }\end{array}$ ethanolic/methanolicextract of Curcuma longa and Curcuma xanthorrhiza, exhibitedanti tyrosinase effect wherein $\mathrm{IC}_{50}$ value estimated were $206.7 \pm 9.2 \mu \mathrm{g} / \mathrm{ml}$ and $267.3 \pm 6.1 \mu \mathrm{g} / \mathrm{mlamong}$ the 35 plants analysedby Batubara et al., 2010 [61]. Further studies were carried out by Lee et al., to depict the inhibitory effect of curcumin against thesignal pathway stimulated by $\alpha \mathrm{MSH}$ and expression of enzymes like tyrosinase, TRP1/TRP2 along with regulating proteins were analysed in B16F10 cells [62]. The work carried out by Mustarichie et al., wherein the docking simulation results of curcumin,demethoxycurcumin, xanthorrizol and Kojic Acid was carried out using AutoDock wherein it was seen that Hydrogen bonding and vanderwaal forces of interaction occur with all three actives. All the three compounds Curcumin, 
demethoxycurcumin and xanthorrizol have smaller interaction energy than kojic acid, due to these three having high binding affinity at the active site of enzyme [63]. The study indicated that these compounds can be used as whitening agent as a safe substitute to the use of kojic acid reported as a carcinogen.

\section{Stilbene Derivatives}

Resveratrol oligomers (3,4,5-trihydroxy-transstilbene), obtained from the plants of Dipterocarpaceae plants were studied against murine tyrosinase. The molecular size along with double bond in the trans stilbene structure is important for the inhibitory effect [64]

\section{CONCLUSION}

Pigment disorders are caused by up regulation or down regulation of tyrosinase. Tyrosinase isratelimiting enzyme in the melanogenesis process and can be a potential target for tyrosinase inhibitors. Natural tyrosinase inhibitors are preferred over their synthetic analogs owing to the safety and can be used irrespective of the span of time for treatment as they also have other synergistic effects nourishing the skin. Plants are rich in Polyphenols which form building blocks for the biosynthesis of chalcone, flavones, flavanols and flavonoids which further form proanthocyanidins and contribute as antioxidants. However, as these phytoconstituent have poor solubility and stability when formulated in different matrix their bioavailability becomes a major concern. With the molecular docking studies, significance of hydroxyl groups in polyphenols at specific positions correlates with its binding energy and is in coherence with the enzyme inhibition assay.This study further can help indevelopment of structural analogs with desired modification to enhance activity, stability and safety for long term use in skin care.

\section{Conflicts of Interest}

The authors report no conflicts of interest. The authors alone are responsible for the content and writing of this article.

\section{Acknowledgement}

The author are happy to acknowledge Dr. Sohan Chitlange sir for providing valuable insight regarding topic and also thankful to Dr. D Y Patil Institute of Pharmaceutical Science and Research, Pimpri, Pune for facility support during manuscript preparation.

\section{REFERENCES}

1. Ortonne, J. P., Arellano, I., Berneburg, M., Cestari, T., Chan, H., Grimes, P, Hexsel, D., Im, S., Lim, J., Lui, H., \& Pandya, A. (2009). A global survey of the role of ultraviolet radiation and hormonal influences in the development of melisma. Journal of the European Academy of Dermatology and Venereology. 23(11):1254-62.

2. Sharma, V. K., Sahni, K., \& Wadhwani, A. R. (2013). Photodermatoses in pigmented skin. Photochemical \& Photobiological Sciences. 12(1):65-77.

3. Tefekli, A., Karadag, M. A., Tepeler, K., Sari, E., Berberoglu, Y., Baykal, M., ... \& Muslumanoglu, A. Y. (2008). Classification of percutaneous nephrolithotomy complications using the modified clavien grading system: looking for a standard. European urology, 53(1), 184-190.

4. Vashi, N. A., \& Kundu, R. V. (2013). Facial hyperpigmentation: causes and treatment. British Journal of Dermatology, 169, 41-56.

5. Taylor, S. C. (2002). Skin of color: biology, structure, function, and implications for dermatologic disease. Journal of the American Academy of Dermatology, 46(2), S41-S62.

6. Nouveau, S., Agrawal, D., Kohli, M., Bernerd, F., Misra, N., \& Nayak, C. S. (2016). Skin hyperpigmentation in Indian population: Insights and best practice. Indian journal of dermatology, 61(5), 487.

7. Fernandez, X., Michel, T., \& Azoulay, S. (2015). Actifs cosmétiques à effet blanchissant-Nature, efficacité et risques.

8. Porta, E. A. (2002). Pigments in aging: an overview. Annals of the New York Academy of Sciences. 959(1):57-65.

9. Ezzedine, K., Sheth, V., Rodrigues, M., Eleftheriadou, V., Harris, J. E., Hamzavi, I. H., \& Pandya, A. G. (2015). Vitiligo is not a cosmetic disease. Journal of the American Academy of Dermatology, 73(5), 883-885.

10. Iannella, G., Greco, A., Didona, D., Didona, B., Granata, G., Manno, A., ... \& Magliulo, G. (2016). Vitiligo: pathogenesis, clinical variants and treatment approaches. Autoimmunity reviews, 15(4), 335-343.

11. Tunzi, M., \& Gray, G. R. (2007). Common skin conditions during pregnancy. American family physician, 75(2), 211-218.

12. Brenner, M., \& Hearing, V. J. (2008). The protective role of melanin against UV damage in human skin. Photochemistry and photobiology, 84(3), 539-549.

13. Dembitsky, V. M., \& Kilimnik, A. (2016). Antimelanoma agents derived from fungal species. $\mathrm{M}$ J Pharma, 1:1-16.

14. Maghsoudi, S., Adibi, H., Hamzeh, M., AshrafiKooshk, M. R., Rezaei-Tavirani, M., \& Khodarahmi, R. (2013). Kinetic of mushroom tyrosinase inhibition by benzaldehyde derivatives. J Rep Pharm Sci, 2, 156-164.

15. Bagherzadeh, K., Shirgahi Talari, F., Sharifi, A., Ganjali, M. R., Saboury, A. A., \& Amanlou, M. (2015). A new insight into mushroom tyrosinase inhibitors: docking, pharmacophore-based virtual 
Lata Kothapalli et al., Saudi J Med Pharm Sci, Feb, 2021; 7(2): 135-144

screening, and molecular modeling studies. Journal of Biomolecular Structure and Dynamics, 33(3), 487-501.

16. Ismaya, W. T., Rozeboom, H. J., Weijn, A., Mes, J. J., Fusetti, F., Wichers, H. J., \& Dijkstra, B. W. (2011). Crystal structure of Agaricus bisporus mushroom tyrosinase: identity of the tetramer subunits and interaction with tropolone. Biochemistry, 50(24), 5477-5486.

17. Sendovski, M., Kanteev, M., Ben-Yosef, V. S., Adir, N., \& Fishman, A. (2011). First structures of an active bacterial tyrosinase reveal copper plasticity. Journal of molecular biology, 405(1), 227-237.

18. Chang, T. S. (2009). An updated review of tyrosinase inhibitors. International journal of molecular sciences, 10(6), 2440-2475.

19. Mukherjee, P. K., Biswas, R., Sharma, A., Banerjee, S., Biswas, S., \& Katiyar, C. K. (2018). Validation of medicinal herbs for anti-tyrosinase potential. Journal of herbal medicine, 14, 1-16.

20. Lee, S. Y., Baek, N., \& Nam, T. G. (2016). Natural, semisynthetic and synthetic tyrosinase inhibitors. Journal of Enzyme Inhibition and Medicinal Chemistry, 31(1), 1-13.

21. Pillaiyar, T., Manickam, M., \& Jung, S. H. (2015). Inhibitors of melanogenesis: a patent review (2009-2014). Expert opinion on therapeutic patents, 25(7), 775-788.

22. Sánchez-Ferrer, Á., Rodríguez-López, J. N., García-Cánovas, F., \& García-Carmona, F. (1995). Tyrosinase: a comprehensive review of its mechanism. Biochimica et Biophysica Acta (BBA)-Protein Structure and Molecular Enzymology, 1247(1), 1-11.

23. Solano, F. (2014). Melanins: skin pigments and much more-types, structural models, biological functions, and formation routes. New Journal of Science, 2014.

24. Chang, T. S. (2012). Natural melanogenesis inhibitors acting through the down-regulation of tyrosinase activity. Materials, 5(9), 1661-1685.

25. Muñoz- Muñoz, J. L., Garcia- Molina, F., Varon, R., Garcia- Ruíz, P. A., Tudela, J., GarciaCánovas, F., \& Rodríguez- López, J. N. (2010). Suicide inactivation of the diphenolase and monophenolase activities of tyrosinase. IUBMB life, 62(7), 539-547.

26. Matoba, Y., Kumagai, T., Yamamoto, A., Yoshitsu, H., \& Sugiyama, M. (2006). Crystallographic evidence that the dinuclear copper center of tyrosinase is flexible during catalysis. Journal of Biological Chemistry, 281(13), 8981-8990.

27. Bijelic, A., Pretzler, M., Molitor, C., Zekiri, F., \& Rompel, A. (2015). The structure of a plant tyrosinase from walnut leaves reveals the importance of "Substrate- Guiding Residues" for enzymatic specificity. Angewandte Chemie International Edition, 54(49), 14677-14680.

28. Sardana, K., \& Ghunawat, S. (2015). Rationale of using hypopigmenting drugs and their clinical application in melasma. Expert review of clinical pharmacology, 8(1), 123-134.

29. Land, E. J., Ramsden, C. A., \& Riley, P. A. (2007). The mechanism of suicide-inactivation of tyrosinase: a substrate structure investigation. The Tohoku journal of experimental medicine, 212(4), 341-348.

30. Park, J., Jung, H., Kim, K., Lim, K. M., Kim, J. Y., Jho, E. H., \& Oh, E. S. (2018). D- tyrosine negatively regulates melanin synthesis by competitively inhibiting tyrosinase activity. Pigment cell \& melanoma research, 31(3), 374-383.

31. Zolghadri, S., Bahrami, A., Hassan Khan, M. T., Munoz-Munoz, J., Garcia-Molina, F., GarciaCanovas, F., \& Saboury, A. A. (2019). A comprehensive review on tyrosinase inhibitors. Journal of Enzyme Inhibition and Medicinal Chemistry, 34(1), 279-309.

32. Sánchez-Ferrer, Á., Rodríguez-López, J. N., García-Cánovas, F., \& García-Carmona, F. (1995). Tyrosinase: a comprehensive review of its mechanism. Biochimica et Biophysica Acta (BBA)-Protein Structure and Molecular Enzymology, 1247(1), 1-11.

33. Kaidbey, K. H., Agin, P. P., Sayre, R. M., \& Kligman, A. M. (1979). Photoprotection by melanin - a comparison of black and Caucasian skin. Journal of the American Academy of Dermatology, 1(3), 249-260.

34. Giada, M. D. L. R. (2013). Food phenolic compounds: main classes, sources and their antioxidant power. Oxidative stress and chronic degenerative diseases-A role for antioxidants. InTech, 87-112.

35. Smit, N., Vicanova, J., \& Pavel, S. (2009). The hunt for natural skin whitening agents. International journal of molecular sciences, 10(12), 5326-5349.

36. Nguyen, M. H. K., Nguyen, H. X., Nguyen, M. T. T., \& Nguyen, N. T. (2012). Phenolic constituents from the heartwood of Artocapus altilis and their tyrosinase inhibitory activity. Natural product communications, 7(2), 1934578X1200700214.

37. Kim, D. C., Kim, S., Hwang, K. S., \& Kim, C. H. (2017). p-Coumaric acid potently down-regulates zebrafish embryo pigmentation: Comparison of in vivo assay and computational molecular modeling with phenylthiourea. Biomedical Science Letters, 23(1), 8-16.

38. Falcone Ferreyra, M. L., Rius, S., \& Casati, P. (2012). Flavonoids: biosynthesis, biological functions, and biotechnological applications. Frontiers in plant science, 3, 222. 
39. Khatib, S., Nerya, O., Musa, R., Shmuel, M., Tamir, S., \& Vaya, J. (2005). Chalcones as potent tyrosinase inhibitors: the importance of a 2, 4substituted resorcinol moiety. Bioorganic \& medicinal chemistry, 13(2), 433-441.

40. Shimizu, K., Kondo, R., \& Sakai, K. (2000). Inhibition of tyrosinase by flavonoids, stilbenes and related 4-substituted resorcinols: structureactivity investigations. Planta medica, 66(01), 1115.

41. Ohguchi, K., Tanaka, T., Iliya, I., ITO, T., IINUMA, M., MATSUMOTO, K., ... \& NOZAWA, Y. (2003). Gnetol as a potent tyrosinase inhibitor from genus Gnetum. Bioscience, biotechnology, and biochemistry, 67(3), 663-665.

42. Kim, D., Park, J., Kim, J., Han, C., Yoon, J., Kim, N., ... \& Lee, C. (2006). Flavonoids as mushroom tyrosinase inhibitors: a fluorescence quenching study. Journal of agricultural and food chemistry, 54(3), 935-941.

43. Shang, C., Zhang, Y., You, X., Guo, N., Wang, Y., Fan, Y., \& Liu, W. (2018). The effect of 7, 8, 4 '- trihydroxyflavone on tyrosinase activity and conformation: Spectroscopy and docking studies. Luminescence, 33(4), 681-691.

44. Dinda, B., Dinda, S., DasSharma, S., Banik, R., Chakraborty, A., \& Dinda, M. (2017). Therapeutic potentials of baicalin and its aglycone, baicalein against inflammatory disorders. European journal of medicinal chemistry, 131, 68-80.

45. Gao, H., Nishida, J., Saito, S., \& Kawabata, J. (2007). Inhibitory effects of 5, 6, 7trihydroxyflavones

tyrosinase. Molecules, 12(1), 86-97.

46. Gao, Y., Snyder, S. A., Smith, J. N., \& Chen, Y. C. (2016). Anticancer properties of baicalein: a review. Medicinal chemistry research, 25(8), 1515-1523.

47. Guo, N., Wang, C., Shang, C., You, X., Zhang, L., \& Liu, W. (2018). Integrated study of the mechanism of tyrosinase inhibition by baicalein using kinetic, multispectroscopic and computational simulation analyses. International journal of biological macromolecules, 118, 57-68.

48. Ismaya, W. T., Rozeboom, H. J., Weijn, A., Mes, J. J., Fusetti, F., Wichers, H. J., \& Dijkstra, B. W. (2011). Crystal structure of Agaricus bisporus mushroom tyrosinase: identity of the tetramer subunits and interaction with tropolone. Biochemistry, 50(24), 5477-5486.

49. Zheng, Z. P., Zhu, Q., Fan, C. L., Tan, H. Y., \& Wang, M. (2011). Phenolic tyrosinase inhibitors from the stems of Cudrania cochinchinensis. Food $\&$ function, 2(5), 259-264.

50. Mendoza-Wilson, A. M., Santacruz-Ortega, H., \& Balandrán-Quintana, R. R. (2011). Relationship between structure, properties, and the radical scavenging activity of morin. Journal of Molecular Structure, 995(1-3), 134-141.

51. Makris, D. P., \& Rossiter, J. T. (2002). Hydroxyl free radical-mediated oxidative degradation of quercetin and morin: a preliminary investigation. Journal of Food Composition and Analysis, 15(1), 103-113.

52. Fang, S. H., Hou, Y. C., Chang, W. C., Hsiu, S. L., Chao, P. D. L., \& Chiang, B. L. (2003). Morin sulfates/glucuronides exert anti-inflammatory activity on activated macrophages and decreased the incidence of septic shock. Life Sciences, 74(6), 743-756.

53. Wang, Y., Zhang, G., Yan, J., \& Gong, D. (2014). Inhibitory effect of morin on tyrosinase: insights from spectroscopic and molecular docking studies. Food chemistry, 163, 226-233.

54. Gil-Izquierdo, A., Gil, M. I., Ferreres, F., \& Tomás-Barberán, F. A. (2001). In vitro availability of flavonoids and other phenolics in orange juice. Journal of Agricultural and Food Chemistry, 49(2), 1035-1041.

55. Liu, L., Shan, S., Zhang, K., Ning, Z. Q., Lu, X. P., \& Cheng, Y. Y. (2008). Naringenin and hesperetin, two flavonoids derived from Citrus aurantium up- regulate transcription of adiponectin. Phytotherapy Research: An International Journal Devoted to Pharmacological and Toxicological Evaluation of Natural Product Derivatives, 22(10), 1400-1403.

56. Garg, A., Garg, S., Zaneveld, L. J. D., \& Singla, A. K. (2001). Chemistry and pharmacology of the citrus bioflavonoid hesperidin. Phytotherapy research, 15(8), 655-669.

57. Si, Y. X., Wang, Z. J., Park, D., Chung, H. Y., Wang, S. F., Yan, L., Yang, J. M., Qian, G. Y., Yin S. J., \& Park, Y. D. (2012). Effect of hesperetin on tyrosinase: Inhibition kinetics integrated computational simulation study. International Journal of Biological Macromolecules. 50(1):257-62.

58. Chai, W. M., Shi, Y., Feng, H. L., Xu, L., Xiang, Z. H., Gao, Y. S., \& Chen, Q. X. (2014). Structure characterization and anti-tyrosinase mechanism of polymeric proanthocyanidins fractionated from kiwifruit pericarp. Journal of agricultural and food chemistry. 62(27):6382-9.

59. Chai, W. M., Wei, M. K., Wang, R., Deng, R. G., Zou, Z. R., \& Peng, Y. Y. (2015). Avocado proanthocyanidins as a source of tyrosinase inhibitors: structure characterization, inhibitory activity, and mechanism. Journal of agricultural and food chemistry. 63(33):7381-7.

60. Chai, W. M., Lin, M. Z., Feng, H. L., Zou, Z. R., \& Wang, Y. X. (2017). Proanthocyanidins purified from fruit pericarp of Clausenalansium (Lour.) Skeels as efficient tyrosinase inhibitors: structure evaluation, inhibitory activity and 
molecular mechanism. Food \& Function. 8(3):1043-51.

61. Batubara, Darusman, L. K., Mitsunaga, T., Rahminiwati, M., \& Djauhari, E. (2010). Potency of Indonesian Medicinal Plants as Tyrosine Inhibitor and Antioxidant Agent. Journal of Biological sciences. 10(2):138-144.

62. Lee, J. H., Ji-Yeom, J., Cheol, P., Byung-Woo, K., Yung-Hyun, C., \& Byung-Tae, C. (2010). Curcumin Suppresses aMelanocyte Stimulating Hormone Stimulated Melanogenesis in B16F10 cells. Int Journal of molecular medicine. 26:101106.

63. Mustarichie, R., Levita, J., \& Febriani, D. (2013). In-silico study of curcumin, demethoxy curcumin and xanthorrizol as skin whitening agents. World Journal of Pharmaceutical Sciences. 1(3):72-80.

64. Ohguchi, K., Tanaka, T., Ito, T., Iinuma, M., Matsumoto, K., Akao, Y., \& Nozawa, Y. (2003). Inhibitory effects of resveratrol derivatives from dipterocarpaceae plants on tyrosinase activity. Bioscience, biotechnology, and biochemistry. 67(7):1587-9. 